\title{
Active Leprosy Treated Effectively with Ofloxacin
}

\author{
Yoko Mochizuki, Minoru Oishi, Chiaki NishiYamA* and Toshihiro IIDA*
}

\begin{abstract}
The patient is a 25-year-old Filipino who showed polymorphous eruptions over the whole body, right ulnar nerve paresis, polyneuropathy and hypalgesia in the area of eruptions. Because the biopsy specimen showed foam cells, histiocytes, epithelioid cells, many Mycobacterium leprae and no giant cells, the diagnosis of borderline-lepromatous $(B L)$ type was made. The symptoms were improved by the administration of $300 \mathrm{mg} / \mathrm{day}$ ofloxacin. Because the monotherapy using ofloxacin has been reported to be effective in all 5 previously reported cases of BL type leprosy, it may be recommended for a larger number of leprosy cases.
\end{abstract}

(Internal Medicine 35: 749-751, 1996)

Key words: borderline-lepromatous, Mycobacterium leprae, biopsy, eruption

\section{Introduction}

Recently, the incidence rate of leprosy in Japan has been very low; only 12 new cases were reported in 1994 (1). Although the World Health Organization (WHO) recommended the combination therapy of dapsone, rifampicin and clofazimine for the treatment of leprosy (2), ofloxacin has recently been reported to be effective (3-5). We report a case of leprosy in which monotherapy using ofloxacin was effective.

\section{Case Report}

The patient is a 25-year-old Filipino male who visited our hospital with the chief complaints of eruptions over his whole body and numbness in the right upper extremity and the bilateral lower extremities on June 7, 1995. He noticed numbness in the left lower extremity in August 1993 and eruptions on the left lower extremity in October 1993 which progressed slowly. He noticed eruptions on his face in January 1994. He has been in Japan since December 1992. His past history and family history were unremarkable.

The physical examination showed multiple infiltrative nodules in the face (left side of Fig. 1) and swelling of the auriculae. There were many round infiltrative eruptions and some depigmented lesions on the trunk and extremities. Hypertrophy of the nervus auricularis magnus, mild weakness of the right abductor digiti quinti muscle and right opponens digiti quinti muscle and mild atrophy of the right opponens digiti quinti muscle were noted. Disturbance of touch, pain, temperature and vibration senses was noted in the right ulnar nerve region and below the knee in both lower extremities. Disturbance of the pain sense was noted in the area of eruptions in the right thigh and left leg.

Laboratory examinations showed that serum angiotensin converting enzyme (ACE) was $37.3 \mathrm{IU} / l$ and that serum $\operatorname{IgG}$ was $1,560 \mathrm{mg} / \mathrm{dl}$. Mycobacterium (M.) leprae was positive in the blood by the polymerase chain reaction (PCR) method. The motor nerve conduction velocities (left/right, $\mathrm{m} / \mathrm{sec}$ ) were 55.9/ 56.4 in the median nerve, $46.0 / 50.0$ in the ulnar nerve, $32.2 / 38.7$ in the peroneal nerve and $36.9 / 35.8$ in the tibial nerve. The sensory nerve conduction velocities were $47.9 / 49.2$ in the median nerve, 46.0/40.2 in the ulnar nerve, 11.4/17.7 in the sural nerve. Needle electromyogram in the right abductor digiti quinti muscle showed positive sharp waves at rest. Biopsy specimen of the left sural nerve showed a decrease in the number of myelinated nerve fibers, axonal degeneration and the infiltration of many histiocytes, epithelioid cells and lymphocytes in the endoneurium (Fig. 2). The biopsy specimen of the facial eruption showed that histiocytes, lymphocytes and epithelioid cells formed many granulomas in the dermis and that macrophages with abundant, foamy cytoplasm, so-called lepra cells, were predominant (Fig. 3). Acid-fast staining showed many $M$. leprae within the foam cells in the eruption, within the histiocytes in the perineurium and peroneal muscle and within the nerve fiber fascicle (Fig. 4).

The treatment using $300 \mathrm{mg} /$ day of ofloxacin was started on June 21. The eruptions, numbness and sensory disturbance began to improve from the end of July. The serum ACE was decreased to normal by the treatment and the needle electromyogram did not show any positive sharp wave after improve-

From the Departments of Neurology and *Dermatology, Nihon University School of Medicine, Tokyo

Received for publication April 3, 1996; Accepted for publication June 18, 1996

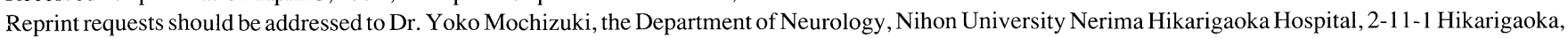
Nerima-ku, Tokyo 179 


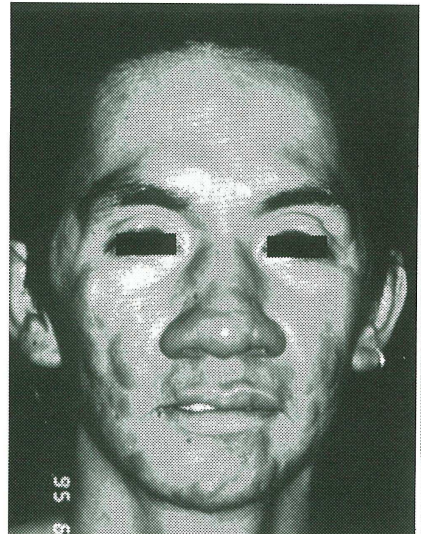

95. 6.7

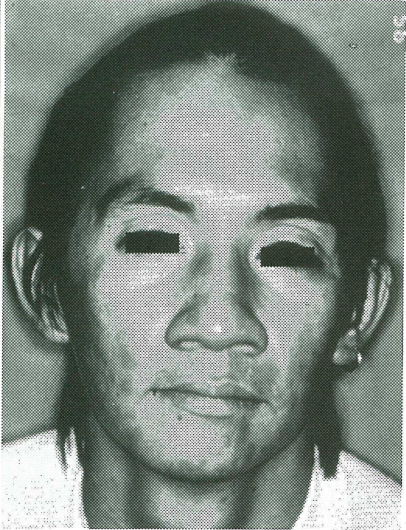

95. 11. 1

Figure 1. Facial eruptions. Left: Before starting the treatment, many soft nodules were noted. Right: The eruptions improved 5 months after starting the treatment.

ment of the symptoms. The eruptions improved in November (Fig. 1).

\section{Discussion}

Because this case showed polymorphous eruptions all over the body, hypertrophy of the nervus auricularis magnus, right ulnar nerve paresis, polyneuropathy and hypalgesia in the area of eruptions and because the biopsy specimen showed foam

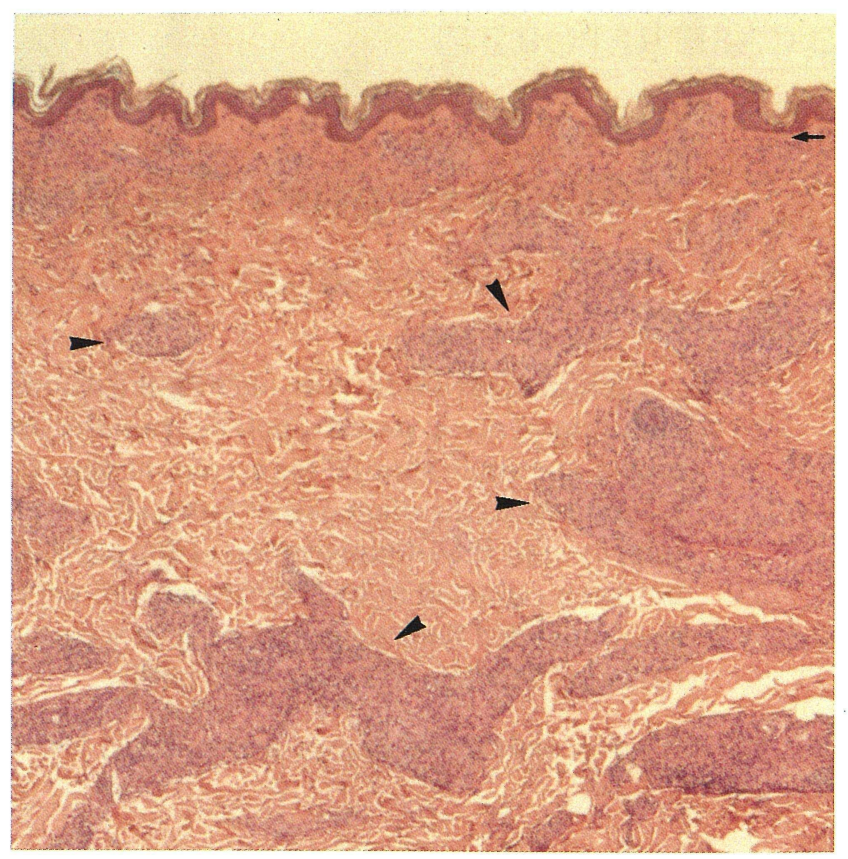

Figure 3. The biopsy specimen of the facial eruption. Many granulomas were seen in the dermis $(\mathbf{A})$. A narrow grenz zone of normal collagen was noted between the flattened epithelium and the lesion in the dermis $(\uparrow)$ (HE stain, $\times 370$ ).

cells, histiocytes, epithelioid cells, many $M$. leprae and no giant cells, we made the diagnosis of borderline-lepromatous
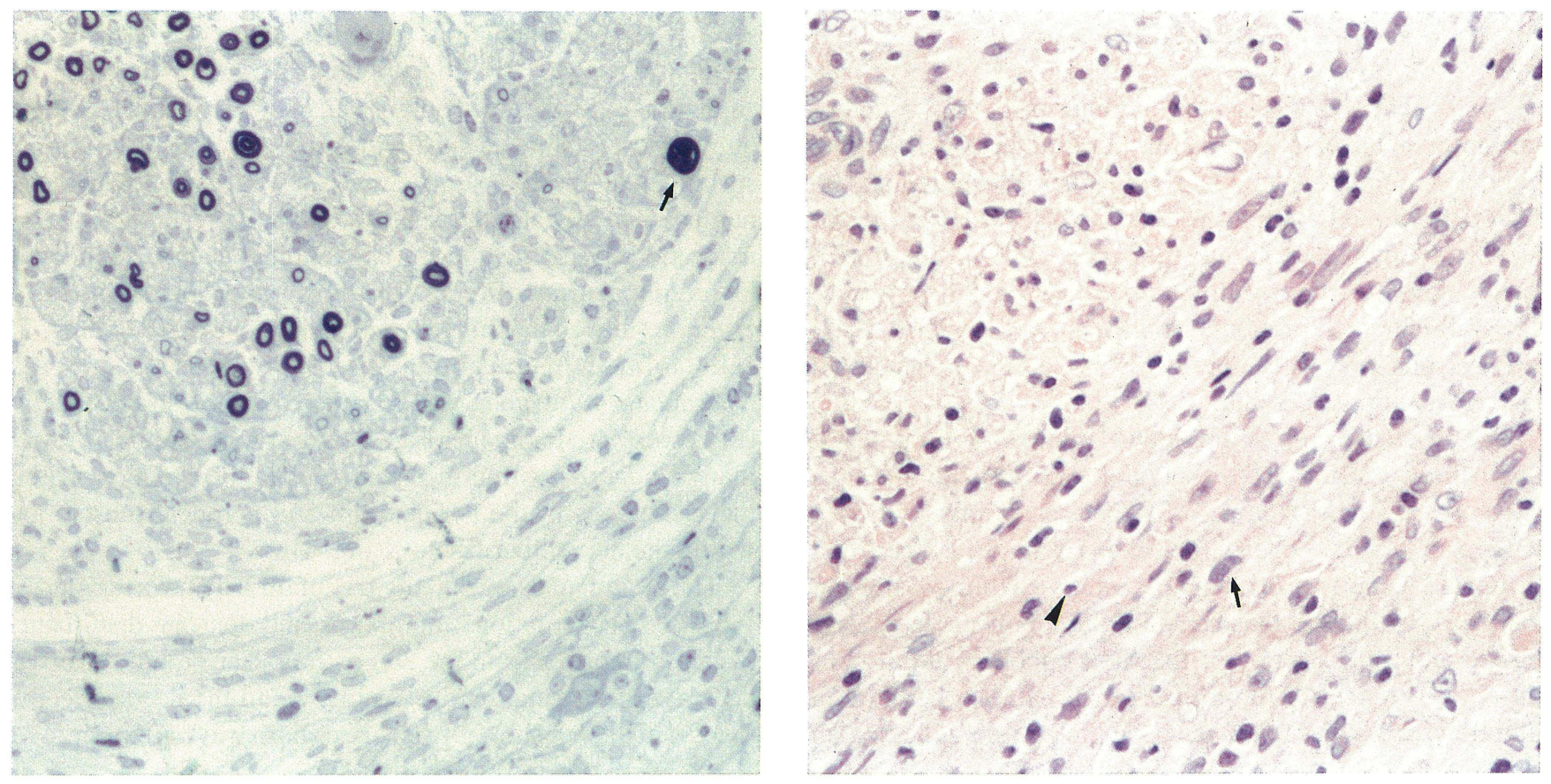

Figure 2. The biopsy specimen of the left sural nerve. Left: A decrease in the number of myelinated nerve fibers, axonal degeneration $(\uparrow)$ and the cellular infiltration in the endoneurium were noted (Toluidine blue stain, $\times 226)$. Right: Infiltration of many histiocytes $(\uparrow)$ and lymphocytes $(\mathbb{A})$ in the endoneurium was noted $(\mathrm{HE}$ stain, $\times 370)$. 

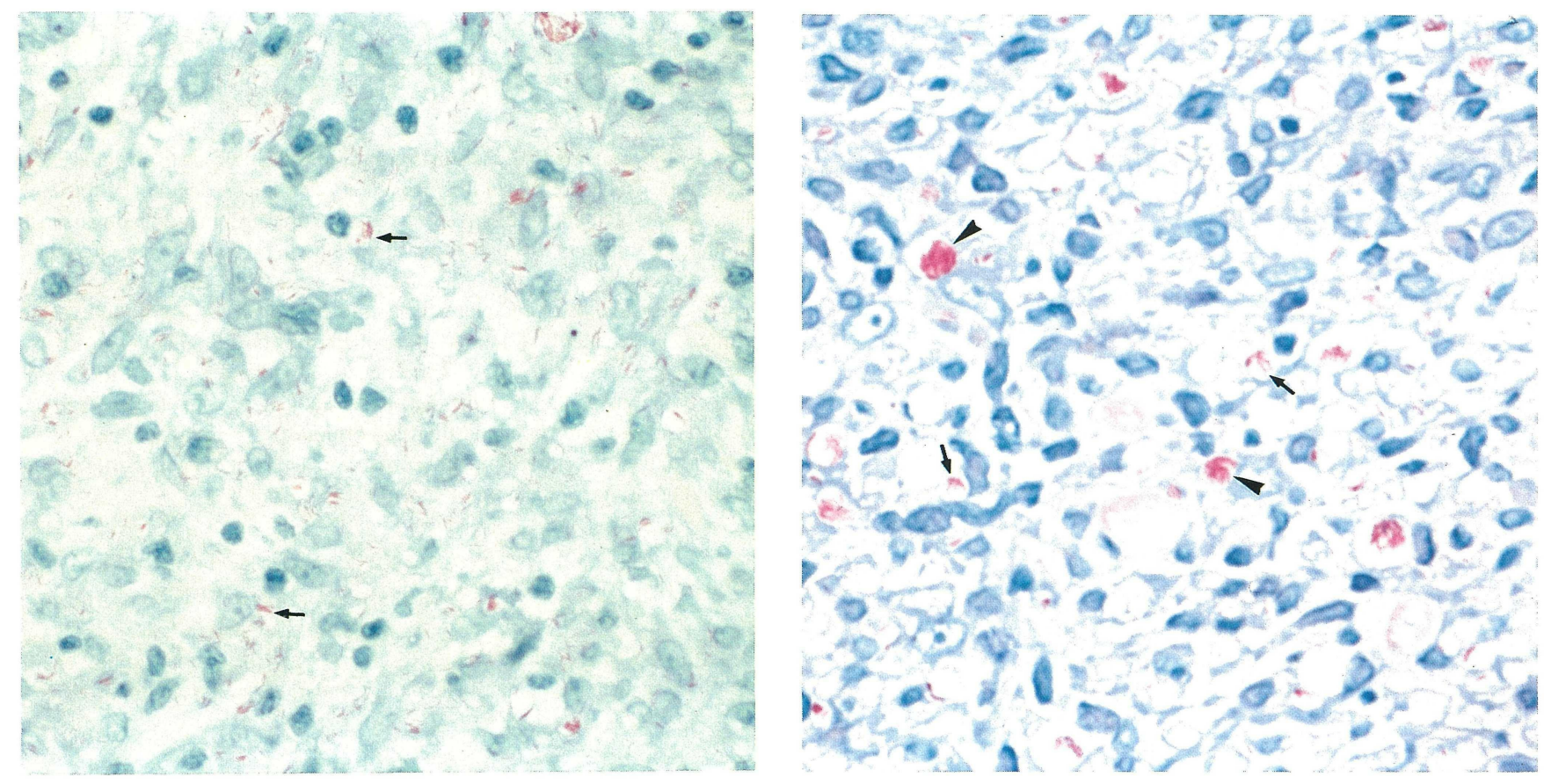

Figure 4. The acid-fast staining. Left: The biopsy specimen of the eruption showed many Mycobacterium leprae within the foam cells $(\uparrow)(\times 490)$. Right: The biopsy specimen of the sural nerve showed many Mycobacterium leprae within the histiocytes $(\uparrow)$ and some fungus balls $(\Lambda)$ were noted $(\times 742)$.

(BL) type according to the classification of the 6th International Congress of Leprosy and the classification of Ridley-Jopling $(6-8)$. New cases of leprosy have been recently rare in advanced countries including Japan (1). The incubation period of leprosy is $4-5$ years on average (9). Because the onset of leprosy was about 8 months after coming to Japan in this case, the transmission of $M$. leprae to this patient was considered to have occurred not in Japan but in the Philippines. It is important to note however, that the onset of leprosy may occur in Japan.

As a treatment for leprosy, WHO recommended a combination therapy using dapsone, rifampicin and clofazimine (2). But this therapy has not been accepted by many leprologists (10). Ofloxacin has been reported to be effective as one of the second generation chemotherapy drugs (3-5). Monotherapy using ofloxacin has been reported in 31 cases of lepromatous (LL) type leprosy (11-13) and in 5 cases of BL type leprosy including the present case $(13,14)$. Because the monotherapy using ofloxacin has been effective in all 5 cases, it should be expanded to be administered on a larger scale.

\section{References}

1) Japanese Ministry of Health. Trends of National Hygiene. Kousei Toukei Kyokai, Tokyo, 1995, p.147 (in Japanese).

2) World Health Organization Study Group. Chemotherapy of leprosy. WHO Tech Rep Ser 847: 12, 1994.

3) Saito $H$, Tomioka $H$, Nagashima $K$. In vitro and in vivo activities of ofloxacin against Mycobacterium leprae infection induced in mice. Int J Lepr 54: 560, 1986.

4) Ji B, Perani EG, Petinon C, Grosset JH. Bactericidal activities of single or multiple doses of various combinations of new antileprosy drugs and/ or rifampin against M. leprae in mice. Int J Lepr 60: 556, 1992.

5) Waters MFR. Chemotherapy of leprosy - current status and future prospects. Trans R Soc Trop Med Hyg 87: 500, 1993.

6) . Classification Committee of Madrid Congress. Madrid classification of leprosy. Draft report of classification committee. Memoria del VI congreso internacional de leprologia. Octubre de 1953, p.75, Madrid.

7) Ridley DS, Jopling WH. Classification of leprosy according to immunity. A five-group system. Int J Lepr 34: 255, 1966.

8) Kato H, Hidano A. Type classification of leprosy - About classification of Ridley-Jopling. Hifu Rinsho 19: 489, 1977 (in Japanese).

9) Gelber RH. Leprosy (Hansen's disease). in: Principles and Practice of Infectious Diseases, 4th edition, Mandell GL, Bennett JE, Dolin R, Eds. Churchill Livingstone Inc, New York, 1995, p. 2243.

10) Style A. Early diagnosis and treatment of leprosy in the United States. Am Fam Physician 52: 172, 1995.

11) Nakama $T$, Miyasato $H$, Maehira F, et al. Treatment of initial infectious lesion and purely neural type of leprosy by floxacin. Nishinihon Hifuka 51: 1220, 1989 (in Japanese).

12) Dietz M, Haas M, Lindner B, Dhople AM, Tebebe YB, Seydel U. Intrabacterial sodium-to-potassium ratios and ATP contents of Mycobacterium leprae from ofloxacin-treated patients. Int J Lepr 59: 548, 1991.

13) Ji B, Perani EG, Petinom C, N'Deli L, Grosset JH. Clinical trial of ofloxacin alone and in combination with dapsone plus clofazimine for treatment of lepromatous leprosy. Antimicrob Agents Chemother 38: 662, 1994.

14) Sugita T, Ozeki M, Yajima M, Iwata M, Ishii N, Nakajima H. A case of leprosy in which ofloxacin showed effectiveness. Nihon Hifuka Gakkai Zasshi 104: 449, 1994 (in Japanese). 